\title{
Active Learning Approach to Enhance Engineering Education in Argentina: A Case of Study in Signals and Systems
}

\author{
Leandro Javier Cymberknop, Ricardo Luis Armentano \\ Department of Electronics, Universidad Tecnológica Nacional, Buenos Aires, Argentina \\ Email: ljcymber@frba.utn.edu.ar
}

How to cite this paper: Cymberknop, L. J., \& Armentano, R. L. (2018). Active Learning Approach to Enhance Engineering Education in Argentina: A Case of Study in Signals and Systems. Creative Education, 9, 1444-1456.

https://doi.org/10.4236/ce.2018.99107

Received: June 30, 2018

Accepted: July 28, 2018

Published: July 31, 2018

Copyright ( 92018 by authors and Scientific Research Publishing Inc. This work is licensed under the Creative Commons Attribution International License (CC BY 4.0).

http://creativecommons.org/licenses/by/4.0/

\begin{abstract}
We are really interested in improving engineering education by applying an original paradigm. For this reason, the undergraduate course of Signal and Systems was selected as our first field of work, to begin the implementation of this new idea and their promotion within our university community. In this regard, the "active learning approach" (AL) is made up of a series of tools that allow the students to become "actively" involved in the course, getting engaged in the activities proposed to enhance their skills rather than trying to assimilate unilaterally imparted information. The idea is to fight against that sort of teaching which does not take into account that each student learns in a singular way and at a specific pace, and not necessarily in a rigid division of levels. We attempt to foster an active discussion about motivation and commitment of the engineering student, analyzing their performance in challenges that stimulate their problem-solving capacity and that are not based on traditional activities.
\end{abstract}

\section{Keywords}

Active Learning, Signals and Systems, Engineering Education in Argentina, Learning by Doing

\section{Introduction}

What motivates a student during his/her academic life? There is a clear distinction between the teaching that transmits content and the learning that receives it. The act of teaching entails focusing and acting on learning processes and results and, in turn, every learning process impacts on the way of teaching. According to a 2016 report of the Secretariat of University Policies of the Ministry 
of education of Argentina, 8313 students obtained their degree in engineering against 34,000 students from social careers, including law and phycology (basically, one engineer per 6300 inhabitants). The graduation rates were between $18 \%$ and $25 \%$ (depending on the career) with a mean duration of seven years (data provided by the Federal Council of Deans in Engineering of Argentina, CONFEDI, in 2016). Particularly, the Universidad Tecnológica Nacional of Argentina is a public institution that comprises the $50 \%$ of engineering students all over the country. Like in others disciplines, the highest dropout rate is observed in the first two years, due to a multiplicity of factors, including the academic ones (Garcia de Fanelli, 2014). Hence, considering this context, two interrogations emerge: How the retention rate could be increased? How to engage students to their activities inside a virtuous cycle? Previous studies have shown that the engineering students (including those of Argentina) tend to prefer active (discussions, application and experimentation), sensory (factual contents and real data), visual (diagrams and figures) and sequential (order and logic) learning styles, which should be emphasized specially during the aforementioned period (Ventura et al., 2014, Felder \& Silverman, 1988). In this sense, a proposal was established in Armentano (2012) that aims engineering students to put their ideas into action and to generate new understandings concomitant to the use of technology, the paradigm of the research oriented to innovation, and more specifically, to combine research with education to translate knowledge to creativity and analytical thinking. For this reason, the Electronic Engineering undergraduate course of Signals and Systems from the Universidad Tecnológica Nacional, in Buenos Aires, was selected as our first field of work, to begin the implementation of this new idea and their promotion within our university community. The application of this original paradigm could help to improve the traditional engineering education, making it more attractive for the students of the early years.

In this regard, the "active learning approach" (AL) is made up of a series of tools that allow the students to become "actively" involved in the course, getting engaged in the activities proposed to enhance their skills rather than trying to assimilate unilaterally imparted information (Keyser, 2000). This work aims at describing the implementation of AL techniques in our Signals and Systems course, selected as a case of study. The idea was to fight against that sort of teaching which does not take into account that each student learns in a singular way and at a specific pace, and not necessarily in a rigid division of levels. We attempt to foster an active discussion about motivation and commitment of the engineering student, analyzing their performance in challenges that stimulate their problem-solving capacity and that are not based on traditional activities.

\section{Active Learning: Motivating Students to Think and Commit Themselves}

The active learning approach $(\mathrm{AL})$ requires students to develop diverse activities 
to generate full consciousness of what they are doing (mental models that are permanently tested) since it is content processing that allows them to learn (Michael, 2006; Keyser, 2000; Carr et al., 2015). It is essentially a student-centered approach where the student determines his pace and learning style and finds support in his peers (Nicol et al., 2017; Prosser \& Trigwell, 2014; Taylor et al., 2012), and where teachers play the role of "guiding and motivating" the student in the process (Nicol et al., 2017; Gilboy et al., 2015). The AL approach may be related to numerous techniques ranging from the traditional resolution of exercises to case studies, learning from experience, learning by "doing", discussion activities or peer learning (Keyser, 2000; Bonwell \& Eison, 1991). Technology plays an important role, but it is not essential, so simulations and games are incorporated together with the use of mobile devices and, eventually, classrooms equipped with high technology (Nicol et al., 2017; Carr et al., 2015). Furthermore, it is widely accepted that AL generates more interest in the student than traditional lectures, and it provides flexibility for the development of the course and fosters a tendency towards the acceptance of individual and group challenges (Keyser, 2000; Michael, 2006). In particular, in engineering education, experimental learning and the group approach offer activities where motivation, creativity and development of tolerance to frustration denote results strongly consolidated towards constructivism. At that stage, students are provided with tools to build their own knowledge, which is modified dynamically, together with the capacity to assess the difficulty of the problem and to decide on the criterion to be used for solving it (Mayer, 2004; Freeman et al., 2014; Carr et al., 2015; Rodriguez Serrano et al., 2012). The inclusion of AL tools (group problem solving, workshops or wireless response systems) versus traditional teaching (continuous and homogeneous exposition by the teacher while participants take notes) has shown an increase in students' performance (especially in small groups) and has had effects on the reduction of academic failure rates (Wright et al., 1998; Freeman et al., 2014). Students learn more effectively when they are tempted to think and apply what they are learning in different configurations, unlike the unequivocal reception of traditional knowledge (Carr et al., 2015). Under such premise, the implementation of AL in undergraduate courses leads to the implementation of activities (performed exclusively by the students) such as: group work, the creation of presentations (online or in class), the participation in discussions on the topics to be dealt with, the development of external work, tutoring of other students, the use of online resources for the search of alternative or complementary information, collaborative work and the interest in carrying out challenging learning activities despite the drawbacks that may emerge (Carr et al., 2015).

\section{Signals and Systems as Case of Study: The Big Challenge}

This subject is placed in a strategic position of the syllabus, between basic mathematical and professional courses. It begins in August and ends in July, in the following year. It lays the foundations for a disruptive and highly motivating 
formative structure, where students deal with applied mathematics and structured reasoning, thus having a great expectation and interest in acquiring new knowledge. Under such premise, the course must be able to provide the students with a constant source of incentives, based on specific challenges that they can face with optimism and curiosity. Signal processing together with system analysis (and design) entail a unique opportunity in the undergraduate program, given its richness in terms of the associated diversity and complexity. Consequently, this course may become the starting point where the student outlines a path purely defined by their own choices from multiple alternatives at their disposal. A traditional teaching approach is usually applied, with lectures given unilaterally by the teacher, combined with classical problems in issues such as: physical systems modeling, frequency domain analysis (Fourier Series and Transform) and signals and systems analysis (Laplace and Z Transforms). In general terms, half of the students use to show substantive difficulties in assimilating specific concepts and part of the mare even unable to finish the course. To overcome this scenario, our proposal regarding the research process was based on the use of different $\mathrm{AL}$ alternatives, mainly focused on improving the experience of learning and promoting discussions (inside and outside the class), which are summarized as follows:

- Access to knowledge through multiple alternatives(visual presentations, videos from the tutor and online resources)

- Systematic and intensive group work, for the fostering of peer learning in different situations(cooperative learning) combined with the use of computational numerical calculation tools to assimilate different contents (learning by doing)

- Acquisition of signals from multiple origins (at the student's choice) for their subsequent treatment in diverse challenges (including their final assignment), and the possibility of short-time internships in the Chair's research groups (education combined with research)

The student is to carry out multiple activities along the process to pass the course, in order to distribute the stress generated by specific evaluation instances. Certain evaluation instances are performed in a dual fashion, where part of the evaluations is solved in group (under the same mechanism of each class) and part, individually. The group assessment approach fosters collaborative work and, out of class, it defines specific roles, it appeals to collective memory and, above all, to discussion (Nicol et al., 2017).

In this first approach, two courses of Signals and Systems of the same cohort (2017-2018) were evaluated. An anonymous and voluntary survey was carried out among the students to determine their general feelings about the different class activities. Questions ranged from a general view of what they thought they had really learned, to specific issues related to the use of the computational numerical tools, working in groups, the discussion of topics in class, the teacher role and their experience with the research activities, among others. 


\subsection{Access to Knowledge}

The structural content of the Signals and Systems course is constituted by visual and written media, which may become both alternative and complementary. In the first place, the student has access to visual presentations from the beginning of the academic year, through the virtual classroom of the course. Such presentations were developed under the concept of "visual notes of the course" so that the student can read and track content before, during and after each class. They combine the traditional theoretical formalism and problem-solving examples with computational numerical solving applications and practical examples in related disciplines. "Group work tasks" are interleaved to create assimilation spaces (Burrowes, 2003). Such structure includes a section where the student can get support in search for an "initial approach" frame of the course content, and it facilitates syllabus completion (Felder \& Brent, 2015). However, such information is discussed (not imparted) in class (we go from monologue to dialogue) and used as a guide for the participation of the groups and the tutors of the course, so as to cope with the lack of knowledge shown by the students. Although it is a highly practical subject, the conceptual aspect is the one that most complicates the students' progress (Herman, 2011). Complementary, there is a series of "integrative talks on video" (developed by the tutor) which provide a global view of the course content, depending on the sections being dealt with. Given that information about general topics such as the Fourier Transform, the sampling theorem or filter theory is easily accessible through the web (seen as 'repository' of information) (Herman, 2011), these lectures constitute an integrating approach that reinforces the connection between the different themes. In this sense, brief talks on History of Science (for instance, the Fourier's setbacks to get his proposal accepted by the Mathematical community or the not so known Euler contributions) become useful to assimilate some contents and promote discussions. This section is also accompanied by recommendations for complementary videos, TED talks, and specific tutorials to provide different "ways of approaching" the course content. In addition, students are encouraged to incorporate knowledge in related topics (in order to promote cross-pollination with other fields), such us Biomedical Engineering MOOCs or the oportunity to become part of online summer schools (Armentano \& Chatterjee, 2015).

\subsection{Systematic and Intensive Group Work}

This approach is based on the "hands-on" concept, by means of specific tasks which are included in the visual notes and must be solved in a given time $(5,10$ and $15 \mathrm{~min}$, since the work is both analytical and numerical). The students work in groups of three, supervised by the course tutors to foster problem-based and peer learning, since it has been shown that cooperative learning leads to better outcomes in students' skills than competition-oriented and competency-based learning (Michael, 2006; Johnson et al., 1998). The aim of each task is to strengthen the knowledge acquired through the analytical evaluation of a problem, complemented by the development of small algorithms of numerical resolution 
(in platforms such as Matlab", Paython or R), to implement a "practical, direct and verifiable image" of the exercise proposed. Such situation offers students freedom to pursue their own interests, focusing mainly on the concept of 'education for autonomy', which establishes non-dependence on the information provided by others (Active Learning in Engineering Education, 2006). Each group is provided with a tablet with Windows 10 and a numerical calculation software, to cope with all the requirements. These devices are connected to a central node (Google Cast for Education platform), which allows the tutor to visualize in an image projected on the wall the content on which each group is working (notes, algorithms, complementary information), essentially for expository purposes. The tasks are organized in two levels: specific tasks (focused on a type of knowledge to be practiced) and integrative tasks, used at the end of each thematic unit to "exploit" the acquired knowledge in a global manner. In particular, in the case of the integrative tasks, the students must solve a motivating problem which consists of analyzing a phenomenon which is different from the topics of the course (case study).

An example of this may be the processing of physiological signals (manipulating the electrocardiogram, blood pressure, the electroencephalogram), the processing of voice in various ways, or the coding and transmission of data, among others. This situation requires additional research by the groups in order to understand the phenomenon under study, which fulfills the students' need to find the "applicability" of the content analyzed. According to the case, the groups solve the tasks simultaneously, or they are assigned specific parts (some the analytical, others the numerical verification). The tasks given must be finished during the class (except for specific cases), discussed and presented (mostly by the students) and finally published on the virtual campus by a designated member of each group. In this way, continuous online feedback is provided to students on the task performed (Carr et al., 2015). Likewise, there is a guide of additional tasks, ordered by level of difficulty, which the student can use in a complementary manner.

A special mention must be given to mobile applications, which are also used in the course in various ways. These include: the use of learning support applications according to the topic being addressed (identified, evaluated and recommended by the students themselves), the implementation of the mobile device as a platform for the visualization of signals in various activities and, on some occasions, their validation against standard devices is proposed in order to promote critical thinking and research work.

\subsection{Acquisition of Signals and Research}

There is a critical need for engineering students to solve problems in their environment in order to become aware of their own abilities. The fundamental role of the teacher must be "to make students do things". For this reason, an integrative project is proposed for the course (incorporation of a project-oriented 
learning approach) to accompany the other learning methods and to encourage students to address topics they are interested in. Such project entails the processing of data of various kinds, measured by the students, and focuses on a challenge in which the students should get fully engaged. This assignment is presented at the end of the course, uploaded to the virtual classroom, and consists of three fundamental questions: 1) What do I want to assess? 2) How will I measure it? 3) Which tools will I use to process it? In the first two instances, students' curiosity and interest is aroused by establishing a connection with research teams working at the university. In other words, they "go in search of answers motivated by their own interests". In particular, they are helped by the Bioengineering Research and Development Group (GIBIO) and the Signal and Image Processing Center (CPSI), which provide them with the necessary means for the acquisition of signals and images (if required) or offer them access to their scientific databases. As well as this, other research laboratories (such as those devoted to solid physics, chemistry and materials) may inform about specific needs they have which may be satisfied by the students, with the possibility to continue working with them in the future. The third question must be answered according to the proposal for the processing of signals used, showing the students' ability to understand the tool chosen for such purpose. An interesting result of this activity is that students recommend web sites, tutorials and learning materials both to their classmates and their tutors, when they find something that truly arouses their interest. Finally, the identification of a model associated with the system from which they have obtained the data results an efficient way in terms of materializing the usefulness of physical systems modelling.

\section{Academic Inter-Operativity}

The convergence for the learning outcomes is usually achieved through the application of the tools acquired in different disciplinary areas. In view of this, it is essential for students to regard the courses of their undergraduate program as a network of interconnected nodes and not as a set of isolated topics. To further this goal, the Signals and Systems course includes not only content addressed in previous courses but also all the content generated by the students which might offer a "natural continuity" to their interests, which are reflected in the final assignments done for other courses and the experimental development platforms explored.

In addition, although the course is part of the undergraduate program, it has a connection with the graduate program: seminars such as "Digital Signal Processing", "Advanced Signal Processing: Adaptive Methods and Neural Networks", "Satellite Image Analysis", "Linear and Non-Linear Systems: Chaos and Fractals" and "Biomedical Imaging Analysis" are part of UTN. BA's Doctoral program with a specialization in Signal and Image Processing (Armentano et al., 2011) and are taught by professors (Doctors in Engineering) who, in turn, have been trained by previous course professors. Such situation created the possibility to carry out complementary activities that are usually very interesting to students, who are eager to apply the knowledge they have. 


\section{Assessing Student Status and Learning}

The follow-up of the students' opinion about the course methodology is formally done by means of anonymous surveys on the virtual campus. These gather information about the material included on the virtual campus, the bibliography available, the use of numerical calculation platforms, the activities performed in class, the complexity and resolution of exams, the impact of the course content on students' daily academic work and the dynamics observed in their work group. Such information is essential given the diversity observed between both groups and individuals. Furthermore, suggestions provided by students can be put in practice by the students themselves, since they can be incorporated into the course as assistants during the next period. Consequently, the Signals and Systems course is continuously adjusting its methodology regarding of the students' response to the different activities.

In academic terms, the system for passing the course is distributed: students obtain credits for tasks completed in class, the integrative group assignment, traditional exams (with both a group and an individual part) and interactive questionnaires (free wireless response platforms such as "Kahoot!"). These questionnaires deal with various thematic units and allow students to test their problem-solving abilities. In addition, they offer students the possibility of receiving "instant" feedback on the knowledge acquired, particularly as a result of the discussion with their classmates (in relation to the correct responses) rather than from their tutors (Carr et al., 2015; Burrowes, 2003). They are solved with the participation of all the members of each group (although they are answered individually) and they contain theoretical/practical questions (of different durations). The resolution of the questionnaires is proposed as a competition (lasting the whole course period) which provides extra points for passing the course "as a reward". This creates a complementary assessment tool (for both groups and individuals) and encourages students to revise content, participate in a ludic activity and make an effort to obtain an acceptable performance before their classmates' eyes.

\section{Preliminary Results}

Although the experience was carried out during an academic period, the opinion of the participating students was gathered $(n=35)$. Essentially, the use of class tasks was regarded as positive, given that their applicability (proposals for fact verification with "content") contributed to understanding the various topics. Also, they were recognized as a good contribution to the course dynamics. The use of numerical calculation tools (used since the beginning of the course and regularly in class) provided training on a versatile tool for visualization, exploration and verification. The visual notes contributed to following the course progress and were usually used to add comments during class discussions. Interactive classes were preferred over in-person lectures. The possibility to do a final assignment gradually, related to each group's research activities, not exces- 
sively demanding (this is part of the learning process) and versatile in relation to the platform and the topic was considered motivating. The development of most class activities as a member of a stable group was well received by participants, due to the evolution of their communicative, discursive (exposition of ideas and concepts) and teamwork abilities. The opportunity to interact with research labs as part of the course activities generated an interesting impact in most of the participants. On the other hand, a small group claimed for a more traditional teaching.

\section{Discussion}

In the present work, AL tools were applied to a Signals and Systems course (as a case of study) that belongs to the Electronic Engineering syllabus of the Universidad Tecnológica Nacional in Argentina. The main objective was to enhance engineering education, appealing to an original paradigm that combines research with education and promotes the development of the student's skills in different aspects of their academic training.

To begin, we think that the general objectives set for a course such as Signals and Systems should be based on the training of professionals with a strong reasoning ability, beyond the systematic learning of operational techniques, in order to achieve a scientific thinking philosophy, applicable to it. The focus should not be placed on teaching content per se but on the content related to facing challenges and specific situations, searching for answers and alternative viewpoints. Teaching content is necessary, which is evident, but insufficient by itself. An interest result obtained from a survey carried out by Cukierman and $\mathrm{Cu}-$ kierman (2013) over 498 participants points out that one of the main challenges faced by Argentine engineering undergraduate students along their career is related to structure of the courses, classifying them as unfair, criticizable or bad. Regarding this, teaching in engineering should be oriented to the upper-right quadrant of the Stokes diagram, called Pasteur quadrant, seeking to concentrate the scientific task according to the existent knowledge, a new way of learning, innovating, communicating and shearing with a creative attitude. Argentina lacks of this kind of engineers, since the focus is put on the lower-left quadrant, the standard engineering applications (Dvorkin, 2014). Hence, students must have a knowledge background and solid qualities that allow them to adapt to uncertain and changing work environments, and to pursue continuing education (Armentano, 2012).

Concerning the content of the Signals and Systems course, concepts related to time-frequency duality (and their applications), the evaluation of analog and digital systems and the correct manipulation of information related to the latter require specific maturation periods and discussion instances, which are not always necessarily proportional to the intensity or amount of exercises related to the topics being studied or even to the time allocated to each content for syllabus completion purposes. For this reason, we worked hard on this issue, proposing periodic integrative discussions. 
Our main ideas are summarized in Figure 1. We consider that the course must be fully aligned with the preeminence of technological innovation, which requires leadership in all aspects of engineering: research as a link between scientific discoveries and practical applications, the teaching of the necessary abilities to create and explore knowledge, and the profession and practice of engineering in order to transform knowledge into competitive products and services (Dvorkin, 2014). By combining research with education, not only do we leverage young people's creativity but we also train them in critical thinking, research methodologies, and solid scientific and engineering knowledge (Armentano, 2012). Furthermore, students must be able to compare the amount of knowledge to be incorporated with the information already processed during the course period, especially in a course like Signals and Systems. It is necessary to avoid content "isolation" resulting from sequencing (by comparing past and present), in order to obtain an integrative picture which allows concepts to be interconnected (Burrowes, 2003; Lord, 1998). Consequently, it is critical for students to apply what they have learned at each step of the way. In our case, we intended to design assignments which move in that direction in order to "surprise" students by proposing concise, tangible and updated tasks.

In our experience, the inclusion of AL has required the establishment of a reference framework for students, with clear and concise guidelines. Students must be listened to, accompanied and their questions must be answered, because they tend to be reticent to commit to the activities and to construct their own knowledge (passive attitude) (Bishop \& Verleger, 2013). Since they are encouraged to developed critical thinking, tutors should be prepared to offer answers. This does not imply that a tutor must be regarded as a guardian of knowledge (clearly an old-fashioned concept), but that they can provide tools for students to construct and assimilate that knowledge (Michael, 2006; Carr et al., 2015). Reflection upon certain topics is strongly required (an even demanded) by students and therefore it should have a privileged role in the course (Burrowes, 2003).

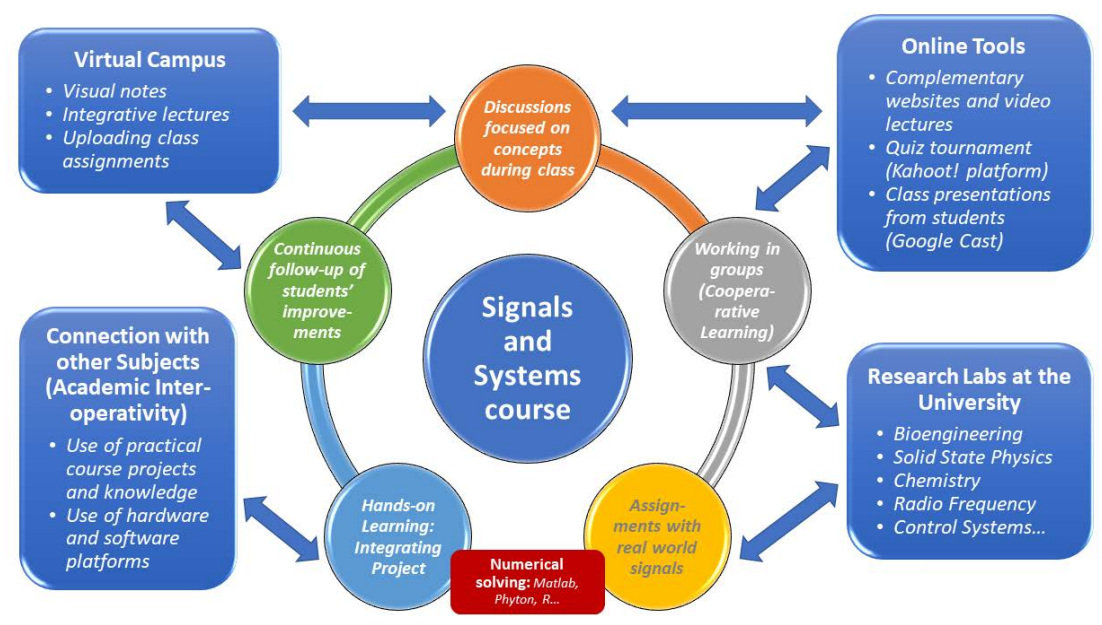

Figure 1. Signals and Systems course dynamics based on Active Learning techniques. 
An essential aspect to consider is the distraction shown by students when solving a task they are not interested in. Since at the end of a lesson students must upload all their productions to the virtual campus for assessment (they obtain points to pass the course), such attitude disrupts the group dynamics and in certain cases it is identified by their classmates, both positively (integration) and negatively (implicit exclusion). In the latter case, it is difficult to motivate someone who is not interested in learning in that way, and thus the analysis of alternative strategies is required (Felder \& Silverman, 1988).

Finally, the effectiveness of AL requires the creation of an ecosystem which allows students to build a network connecting the different courses. It is useless to implement projects of these characteristics if the overall setting (the university as a whole) pushes students in another direction, hindering the appropriate leveraging of the potential shown by this methodology (Rodriguez Serrano et al., 2012; Michael, 2006).

\section{Acknowledgements}

The authors gratefully thank to Dr. Mirian Capelari, Eng. Marcelo Giura, Eng. Alejandro Furfaro and Eng. Marcelo Doallo for their commitment to improve education in engineering at our institution. Additionally, to all our colleagues that are (or have been) professors of the Signals and Systems course and have left their valuable mark in the chair leaded by Dr. Ricardo L. Armentano since 1997. This work was supported by Universidad Tecnólogica Nacional research and development projects ASUTNBA3950 and ICUTIBA4852.

\section{Conflicts of Interest}

The authors declare no conflicts of interest regarding the publication of this paper.

\section{References}

Active Learning in Engineering Education (2006). Best symposium on Education. Porto, Portugal.

Armentano, R. L., Quel, E., Giura, M., Capelari, M., \& Presa, A. (2011). Doctorado en Ingeniería con mención en Procesamiento de Señales e Imágenes Facultad Regional Buenos Aires de la Universidad Tecnológica Nacional. Buenos Aires: Proyecciones, Facultad Regional Buenos Aires.

Armentano, R. L. (2012). Updating Engineering Education in the Southern Cone: Creativity and Innovation. Creative Education, 3, 6A.

https://doi.org/10.4236/ce.2012.326109

Armentano, R. L., \& Chatterjee, P. (2015). MOOC on Biomedical Engineering for Latin American Students-Unleashing the Potential of Virtual Learning. Proceedings of 2015 International Conference on Computational Intelligence and Communication Networks, Jabalpur, 405-410.

Bishop, J. L., \& Verleger, M. A. (2013). The Flipped Classroom: A Survey of the Research. 120th American Society for Engineering Education Annual Conference and Exposi- 
tion, 30, 1-18.

Bonwell, C. C., \& Eison, J. A. (1991). Active Learning: Creating Excitement in the Classroom (p. 2). Washington DC: The George Washington University (ERIC Clearinghouse on Higher Education).

Burrowes, P. A. (2003). Lord's Constructivist Model Put to a Test. The American Biology Teacher, 65, 491-502. https://doi.org/10.2307/4451548

Carr, R., Palmer, S. \& Hagel, P. (2015). Active Learning: The Importance of Developing a Comprehensive Measure. Active Learning in HigherEducation, 16, 173-186. https://doi.org/10.1177/1469787415589529

Cukierman, D., \& Cukierman, U. (2013). Aprender a Aprender: Desafíos que enfrentan los ingresantes a la Universidad y estrategias para mejorar su experiencia educativa y favorecer su retención. Revista Ciencia y Tecnología de la Universidad de Palermo, 13, 389-402. https://doi.org/10.18682/cyt.v1i13.138

Dvorkin, E. N. (2014). Ciencia, tecnología e innovación productiva (Vol. 6, pp. 29-38). Buenos Aires: La educación del Ingeniero para un Mundo cambiante, Luis de Vedia Ed., Academia Nacional de Ciencias Exactas, Físicas y Naturales, Ciudad Autónoma de Buenos Aires.

Federal Council of Deans in Engineering of Argentina. (2016). http://www.confedi.org.ar/

Felder, R., \& Silverman, L. K. (1988). Learning and Teaching Styles in Engineering Education. Engineering Education, 78, 674-681.

Felder, R., \& Brent, R. (2015). Handouts with Gaps. Chemical Engineering Education, 49, 239-240.

Freeman, S. et al. (2014). Active Learning Increases Student Performance in Science, Engineering, and Mathematics. PNAS, 111, 8410-8415.

https://doi.org/10.1073/pnas.1319030111

Garcia de Fanelli, A. M. (2014). Rendimiento académico y abandono universitario: modelos, resultados y alcances de la producción académica en la Argentina. Revista Argentina de Educación Superior, 8, 9-38.

Gilboy, M. B., Heinerichs, S., \& Pazzaglia, G. (2015). Enhancing Student Engagement Using the Flipped Classroom. Journal of Nutrition Education and Behavior, 47, 109-114. https://doi.org/10.1016/j.jneb.2014.08.008

Herman, G. L. (2011). Teaching Signal Processing According to What Your Students Know. In Digital Signal Processing and Signal Processing Education Meeting (pp. 231-236). New York, NY: Institute of Electrical and Electronics Engineers. https://doi.org/10.1109/DSP-SPE.2011.5739217

Johnson, D., Johnson, R., \& Smith, K. (1998). Cooperative Learning Returns to College: What Evidence Is There That It Works? Change, 30, 26-35. https://doi.org/10.1080/00091389809602629

Keyser, M. W. (2000). Active Learning and Cooperative Learning: Understanding the Difference and Using Both Styles Effectively. Research Strategies, 17, 35-44. https://doi.org/10.1016/S0734-3310(00)00022-7

Lord, T. (1998). Cooperative Learning That Really Works in Biology Teaching. Using Constructivist-Based Activities to Challenge Student Teams. The American Biology Teacher, 60, 580-588. https://doi.org/10.2307/4450554

Mayer, R. E. (2004). Should There Be a Three-Strikes Rule against Pure Discovery Learning? The Case for Guided Methods of Instruction. American Psychologist, 59, 14-19.

Michael, J. (2006). Where's the Evidence That Active Learning Works? Advances in Physiology Education, 30, 159-167. https://doi.org/10.1152/advan.00053.2006 
Nicol, A. A., Owens, S. M., Le Coze, S. S., MacIntyre, A., \& Eastwood, C. (2017). Comparison of High-Technology Active Learning and Low-Technology Active Learning Classrooms. Active Learning in Higher Education. https://doi.org/10.1177/1469787417731176

Prosser, M., \& Trigwell, K. (2014). Qualitative Variation in Approaches to University Teaching and Learning in Large First-Year Classes. Higher Education, 67, 783-795. https://doi.org/10.1007/s10734-013-9690-0

Rodriguez Serrano, K. P., Maya Restrepo, M. A., \& Jaén Posada, J. S. (2012). Educación en Ingenierías: De las clases magistrales a la pedagogía del aprendizaje activo. Revista Científica Ingeniería y Desarrollo, 30, 125-142.

Secretariat of University Policies, Ministry of Education, Argentina. http://www.argentina.gob.ar/educacion/politicasuniversitarias

Taylor, L., McGrath-Champ, S., \& Clarkeburn, H. (2012). Supporting Student Self-Study: The Educational Design of Podcasts in a Collaborative Learning Context. Active Learning in Higher Education, 13, 77-90. https://doi.org/10.1177/1469787411429186

Ventura, A. C., Palou, I., Széliga, C., \& Angelone, L. (2014). Estilos de aprendizaje y enseñanza en Ingeniería: Una propuesta de Educación Adaptativa para primer año. Asociación Colombiana de Facultades de Ingeniería; Revista Educación en Ingeniería, 9, 178-189.

Wright, J., Millar, S., Kosciuk, S., Penberthy, D., Wampold, B., \& Williams, P. (1998). A Novel Strategy for Assessing the Effects of Curriculum Reform on Student Competence. Journal of Chemical Education, 75, 986-992. 